\title{
THE CONSERVATIVE TREATMENT OF BENNETT'S FRACTURE-SUBLUXATION OF THE THUMB METACARPAL*
}

\author{
Andrew G. Pollen, Bedford, England \\ From the Bedford General Hospital
}

Since 1882 when Bennett first described the fracture which now bears his name, it has earned a reputation for being simple to reduce but difficult to maintain in position. During the past two decades several authors have expressed disappointment with the results of conservative treatment which, in consequence, has fallen into both disuse and disrepute.

The criteria of recovery are anatomical and functional. There seems little doubt that in the past the late anatomical results as judged from radiographs may have been far from pleasing, but the functional results were often excellent despite imperfect reduction; a lack of correlation that is not unknown in other joint injuries.

In this paper a plea is made for a return to closed methods of treatment. It is claimed that this is an injury very suitable for treatment by manipulation and plaster-of-Paris splintage, and this is supported by an analysis of thirty-one patients so treated.

\section{EARLY METHODS OF TREATMENT}

Bennett was himself dissatisfied with the result of the treatment of his first case. He noted that after nearly two years " the hand fails to grasp or lift with certainty any body requiring a wide gape of the thumb for instance to lift a tumbler full of water from the table, and this in a case where every care was taken to keep the parts in place and at rest for a proper time" (Bennett 1882).

Miles and Struthers (1904) described fifteen cases of this fracture, of which ten were treated by manipulation and splinting the thumb in abduction for two weeks. When reduction could not be achieved the thumb was left free and active movements were encouraged. It is interesting that they considered the prognosis in the untreated patients was good ultimately, although the treated patients achieved good function earlier.

Robinson (1908) was not satisfied with the results of manipulation and splinting the thumb in abduction, because he found that the displacement soon recurred. He devised a method of plaster-of-Paris immobilisation combined with continuous skin traction on the thumb by adhesive strapping attached to buckles incorporated into the plaster splint. He had to adjust the traction strapping frequently to maintain the tension.

This method was the forerunner of established techniques of conservative treatment; the application of a well moulded plaster after manipulative reduction and the incorporation of a method of continuous traction, as described by Ehalt (1929), Roberts (1938), Watson-Jones (1955), Böhler (1956) and others.

This method of treatment has been modified by some workers who felt that skin traction was not adequate to maintain the position of the metacarpal and therefore substituted skeletal traction. Bunnell (1956) employed a pin which transfixed the head of the metacarpal bone, and Spångberg and Thorén (1963) used a wire passing through the metacarpal base and then bent to form a hook. Traction was applied to the distal end of the wire from a metal frame extending beyond the thumb, secured to the hand by plaster-of-Paris.

During the last decade several surgeons reviewed the results of conservative treatment of Bennett's fracture and found them disappointing. Gedda (1954) reviewed forty-four patients treated by manipulation and plaster, undoubtedly the largest series studied in detail. Thirtyfour showed no improvement in position after reduction when the radiographs were reviewed,

* Based on a paper read at a meeting of the British Orthopaedic Association in October 1965. 
and only twenty-one had achieved full function at the conclusion of treatment. However, when forty of these patients were reviewed at a later date, thirty-seven had achieved full working capacity and did not complain of pain. Evidently the functional results in this series were far superior to the radiographic appearances.

Iselin, Blanquernon and Benoist (1956) reviewed eight patients who had been treated conservatively with particular attention to the range of thumb movements. They found that abduction was restricted in five of them. Griffiths (1964) reviewed thirty-four patients treated conservatively and found that in only fifteen was the reduction complete. However, of twenty-one patients from the original group who were subsequently reviewed, only one had marked symptoms and fourteen had no symptoms. He considered that more complex methods of treatment were not indicated unless full restoration of thumb movements was essential.

In recent years the only author who has wholeheartedly advocated conservative treatment is Charnley (1957) who described a method of manipulative reduction and plaster immobilisation without any form of continuous traction; indeed he believed that traction might be a principal cause of the failure of conservative methods.

Operative methods-A pioneer surgeon in this field was Lambotte (1913) who described a method of open reduction and internal fixation of the fragments with a fine nail. The method was illustrated by radiographs of a patient on whom he had operated in 1908. But it is in the last twenty years that operative methods have become increasingly popular, particularly in France and the United States. The problem has been approached in two ways: firstly, by direct exposure of the fracture and fixation of the fragments with wires or a small screw, and, secondly, by reducing the fracture by manipulation and stabilising the reduction by passing one or more wires through the metacarpal bone into adjacent bones. Gedda and Moberg (1953) described a volar approach to the fracture, which they fixed with one or more wires passing through the small fragment into the bigger part of the bone. Gedda (1954) reviewed twenty-nine patients treated in this way; complete anatomical reduction was obtained in twenty, but full function was achieved in every case. In this country Badger (1956) reported seventeen patients treated by open reduction and screw fixation. No plaster-of-Paris immobilisation was required after operation in contradistinction to all other methods. Vaughan-Jackson (1956) also recommended open reduction, but he fixed the fragments with a pin. Other British authors who have advocated operative treatment are Furlong (1957), Robins (1961) and Clarkson and Pelly (1962).

The technique of combining manipulative reduction with skeletal fixation was adopted by Johnson (1944). He stabilised the reduction by passing one or two wires through the thumb metacarpal into the index metacarpal bone. Wagner $(1950,1951)$ used a similar technique but passed the wire through the base of the first metacarpal into the trapezium, transfixing the joint. He treated thirty-eight fractures in this way. Wiggins, Bundens and Park (1954) modified this method and treated twenty-eight fractures, with good results in twenty-six.

In France similar methods have been employed by several groups of surgeons. Menegaux and Detrie (1953) adopted the technique of Wagner (1950), and Iselin et al. (1956), Creyssel, de Mourgues and Schnepp (1959), Lataste and Cédard (1959) and Razemon and Lemerle (1959) all used similar methods.

A different operative technique which does not fall into either of the former categories was described by Ellis (1946). He exposed the trapezio-metacarpal joint and inserted two pins into the lateral margin of the articular surface of the trapezium which formed a buttress to prevent the base of the metacarpal from redisplacing.

\section{SURGICAL ANATOMY}

The causes of the inherent instability of this fracture subluxation after reduction are anatomical. The configuration of the distal articular surface of the trapezium, usually described 
as " saddle shaped," predisposes to the instability. The joint surface is markedly convex in the plane of flexion and extension, and the base of the metacarpal bone is only anchored firmly at its volar aspect by a localised thickening of the capsule forming the volar ligament. It is this portion of the metacarpal base, to which is attached the volar ligament, that remains tehind as the volar fragment when the fracture occurs. The remainder of the metacarpal bone tends to slide down the slope aided by the pull of the abductor pollicis longus tendon, and off the trapezium. Normally the muscle abducts the metacarpal bone away from the palm using the volar ligament as a fulcrum, but, with this fulcrum broken, the pull draws the metacarpal base off the trapezium.

\section{RADIOLOGY}

A radiological study of the fractures has suggested a division into two groups.

Group 1-This includes most cases; the volar fragment varies in size from a small piece of cortical bone attached to the volar ligament to a relatively large triangular-shaped fragment of which the base may comprise up to half of the articular surface of the metacarpal. The two

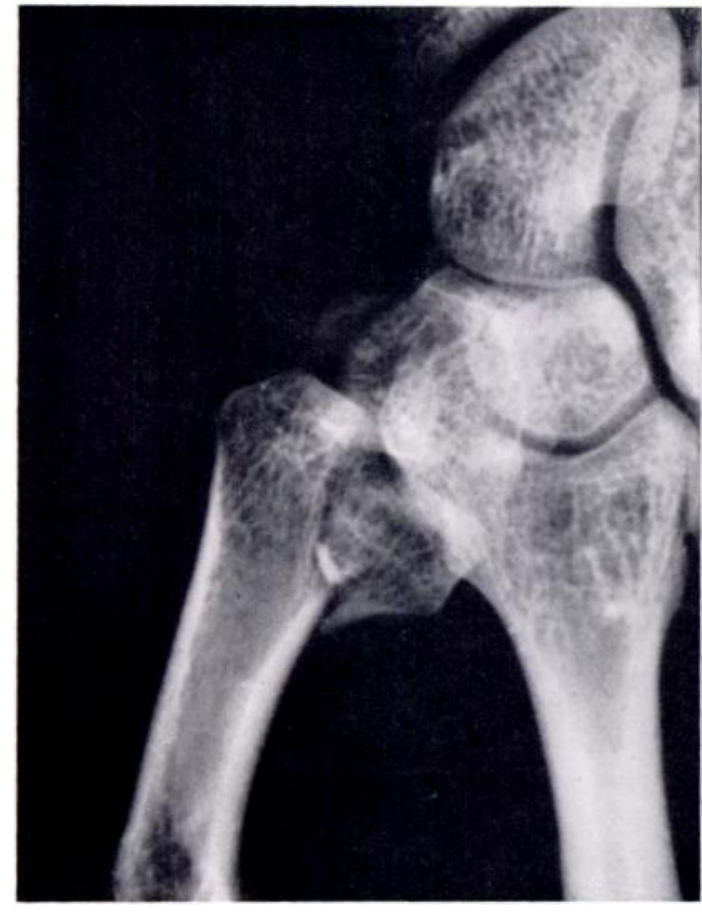

FiG. 1

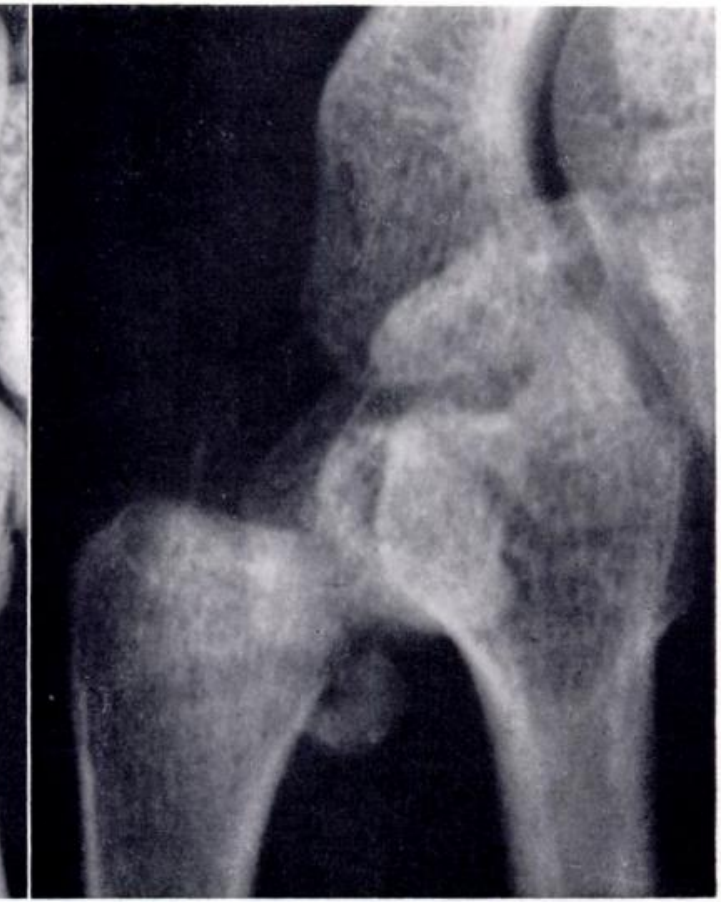

FIG. 2

Figure 1-Radiograph showing a Group 1 fracture with a large volar fragment. Figure 2-Radiograph showing a Group 2 fracture with a small volar fragment and much displacement of the main fragment.

fragments are rotated away from each other leaving a gap in the articular surface, but sometimes the volar fragment is completely sheared off, leaving a "step" in the articular surface as shown in Figure 1.

There is always some contact between the fragments at the apex of the volar fragment. The degree of displacement is best assessed clinically rather than by relying upon the radiographic appearance, which may be deceptive.

Group 2-These fractures are characterised by the separation of a tiny volar fragment from the metacarpal base. The latter is displaced considerably so that there is no contact between the two fragments (Fig. 2). The reason for considering these cases separately is that it is 
possible to reduce these fractures by manipulation even after several weeks have elapsed. A possible explanation is that the lack of contact between the fragments delays union. In Group 1 healing starts early, and late manipulation is less likely to be successful.

\section{PRINCIPLES OF MANIPULATIVE REDUCTION}

Displacement of the main fragment can be completely reduced by gentle pressure on the metacarpal base to push it inwards along the articular surface of the trapezium towards its volar fragment, when it can be felt to click into position (Fig. 3). But, as is well known, the reduction is unstable and as soon as the pressure is released the displacement recurs. Although it is not possible to hold the metacarpal fracture in such a position that the reduction is completely stable, yet by placing it in a position of moderate extension and abduction the displacing effect of abductor pollicis longus is lessened. Traction on the thumb is unnecessary.

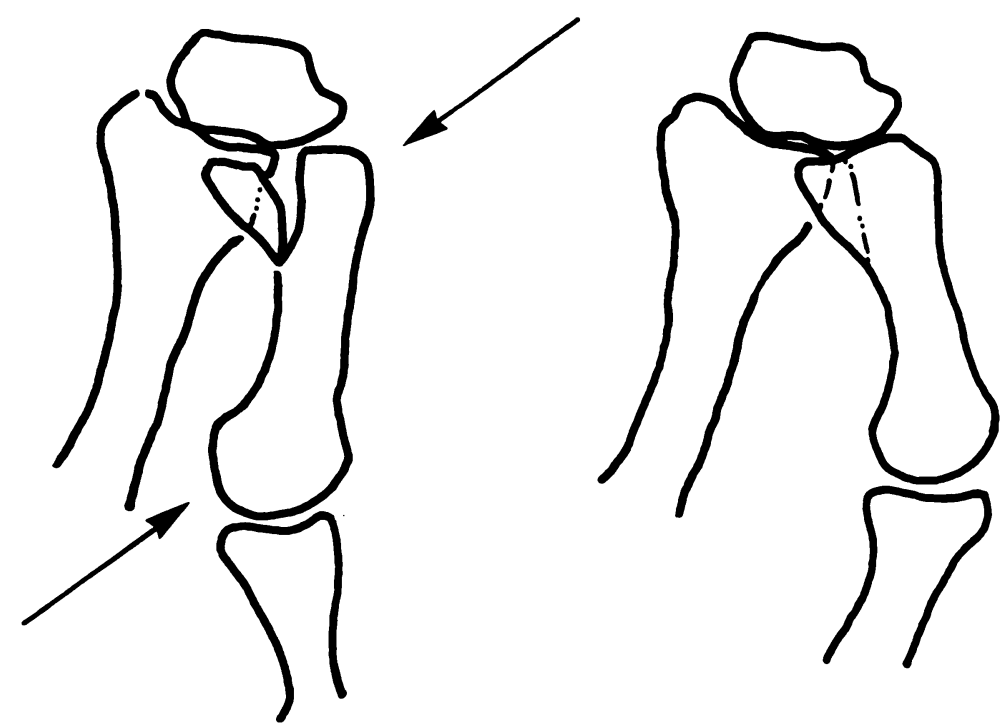

Fig. 3

The method of manipulation, showing how the forces are applied about the first metacarpal bone.

The whole problem of treatment is the maintenance of the gentle pressure on the base of the metacarpal fracture until it has united, which takes four weeks. The solution to the problem is to use a well-fitting plaster suitably padded to prevent skin necrosis at the pressure points. For this purpose the usual plaster wool used as padding is useless, because it displaces wherever localised pressure is applied. Orthopaedic adhesive felt is an ideal material for this purpose because it is slightly compressible and has sufficient elasticity to regain its bulk when the pressure is released. (1957).

The general principles of the author's technique follow the method described by Charnley

Technique of reduction and application of plaster-A trial reduction is done without anaesthesia and before the application of the felt padding. The purpose of this trial is to "get the feel " of the reduction and in particular the palpable click as the bone is reduced, and also to enable the patient to recognise the sensation of reduction so that he may be able to inform the surgeon if he feels it slip during the plastering. Provided that the patient tolerates the procedure thus far, the surgeon can proceed with the definitive manipulation and application of plaster without an anaesthetic. Should the " trial" prove too uncomfortable then it must be abandoned, and the fracture manipulated with anaesthesia. 
A piece of adhesive felt one-eighth of an inch thick and one inch square is applied accurately over the base of the metacarpal of the thumb, and a larger piece is cut to shape to fit the hand and wrist to protect the bony prominences, in particular the metacarpal head and the ulnar border of the hand and wrist. Stockinette is used to protect the remainder of the forearm. A plaster is applied to the hand, thumb and forearm using about six thicknesses, and while it is still soft the fracture is reduced by direct pressure on the base of the thumb metacarpal. At the same time the fingers of the left hand press against the head of the thumb metacarpal bone to hold it in a position of moderate extension and abduction. It should be possible to feel the bone click into position-though the sensation is blunted by the felt and plaster-but the patient may feel the click if an anaesthetic is not used.

The gentle pressure is maintained without alteration of the hold until the plaster has hardened sufficiently, when it may be reinforced and trimmed so that the distal phalanx of the thumb is free and the metacarpo-phalangeal joints of the fingers are unrestricted.

After reduction a radiograph is taken with the palm and the thumb resting on the film. This single projection is sufficient to confirm the reduction. Further radiographs are taken at one and two weeks after reduction to confirm that displacement has not recurred.

The plaster is removed after four weeks, during which period it does not need to be changed, and a final radiograph is taken. Thereafter the patient is told to use the thumb within the limits of comfort but to avoid any heavy work for a further month. Many patients obtain a full range of thumb movements within two weeks of removal of the plaster, and almost all have a full range after four weeks.

\section{REVIEW OF THIRTY-ONE FRACTURES}

Thirty-one patients have been treated by the author from 1958 to 1964 by manipulation and plaster. All except one were male and the ages ranged from sixteen to sixty years, with an average of thirty-five and a half. The right and left thumbs were involved in nearly equal

TABLE I

The Cause of InJury

\begin{tabular}{|c|c|}
\hline Cause & Number \\
\hline Fall & 9 \\
\hline Fight & 8 \\
\hline Sports injury . & 6 \\
\hline Road traffic accident & 5 \\
\hline Injury at work & 3 \\
\hline Total . & 31 \\
\hline
\end{tabular}

TABLE II

RESULTS OF TREATMENT

\begin{tabular}{|c|c|}
\hline Number of fractures. & 31 \\
\hline Manipulation successful . & 30 \\
\hline $\begin{array}{l}\text { Manipulation failed. } \\
\text { Operation }\end{array}$ & 1 \\
\hline $\begin{array}{c}\text { Subsequent slip. } \\
\text { Operation }\end{array}$ & 1 \\
\hline Number of successful cases & 29 \\
\hline Number of failures & 2 \\
\hline
\end{tabular}

numbers, fifteen being on the left and sixteen on the right. Three patients had started treatment at other hospitals but required remanipulation.

Causes of the fracture-Traditionally the injury is sustained during a fight but the name of "stave fracture" sometimes applied to this injury derives from the Scottish vernacular, a stave being a " sprain" according to Miles and Struthers (1904). In this series the commonest cause of the injury was a fall and the next commonest was a fight or boxing match (Table I).

Anatomical results - In thirty of our thirty-one patients an excellent reduction was obtained by manipulation, and in twenty-nine the reduction was maintained until the fracture had united. In two patients this treatment was unsuccessful and open operation was done (Table II).

VOL. $50 \mathrm{~B}$, NO. 1, FEBRUARY 1968 


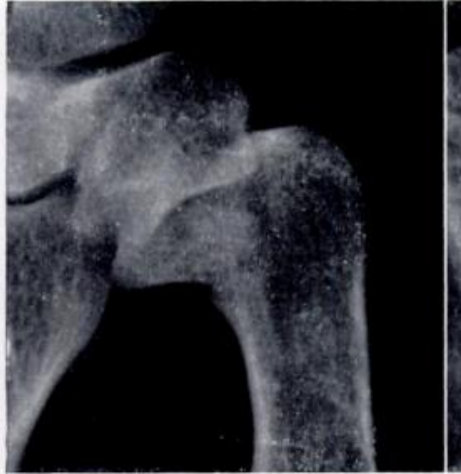

FIG. 4

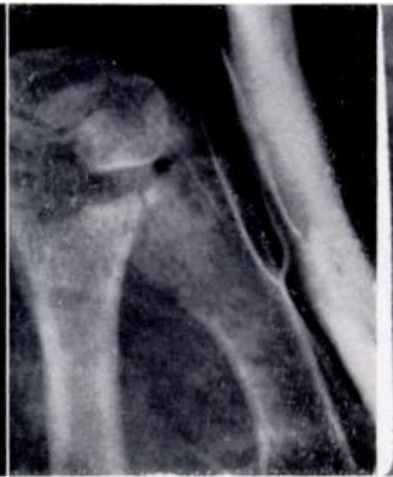

Fig. 5

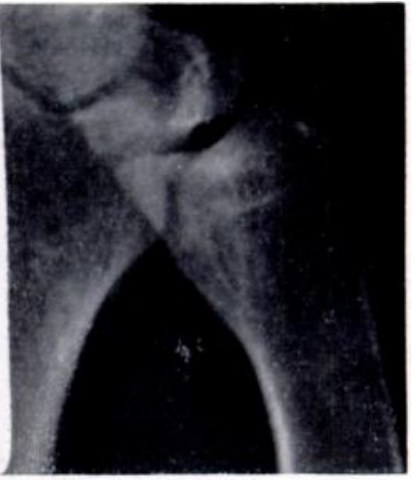

FIG. 6

Case 1. Figure 4-A radiograph showing a Group 1 fracture with considerable rotation of the small fragment. Figure 5-After manipulation there has been complete reduction. Figure 6-After removal of the plaster when the line of the fracture has disappeared.

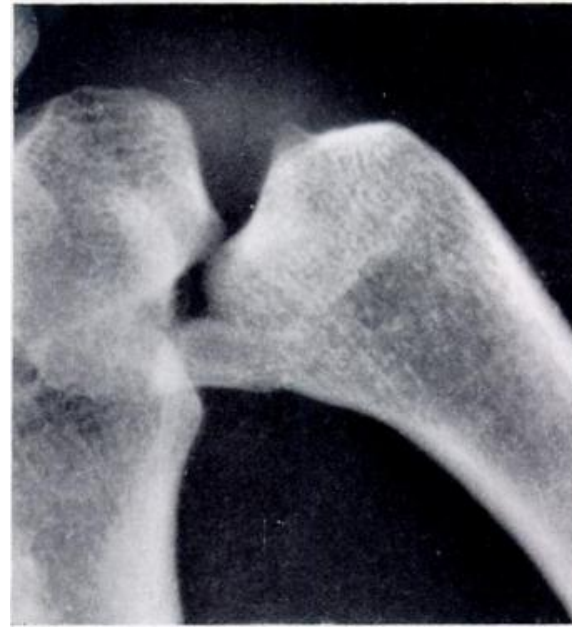

FIG. 7

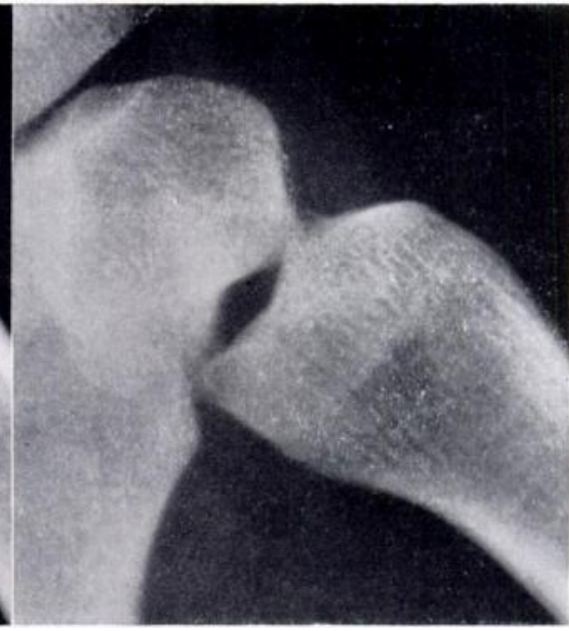

FIG. 8

Case 2. Figure 7-A radiograph showing the fracture which was manipulated without an anaesthetic. Figure 8-Four weeks later the radiograph shows the fracture to have united.

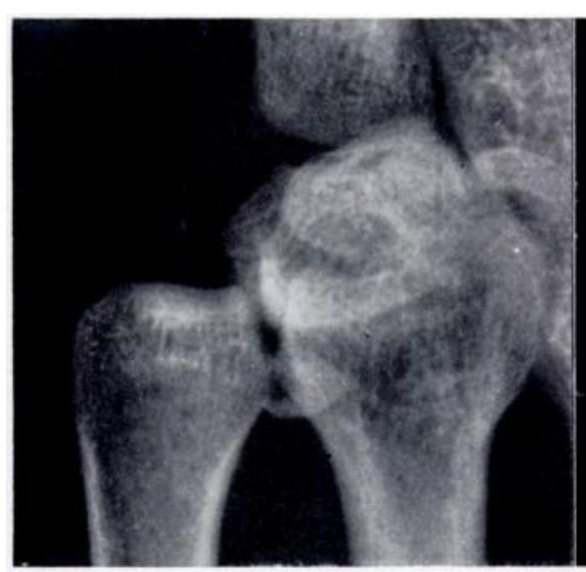

Fig. 9

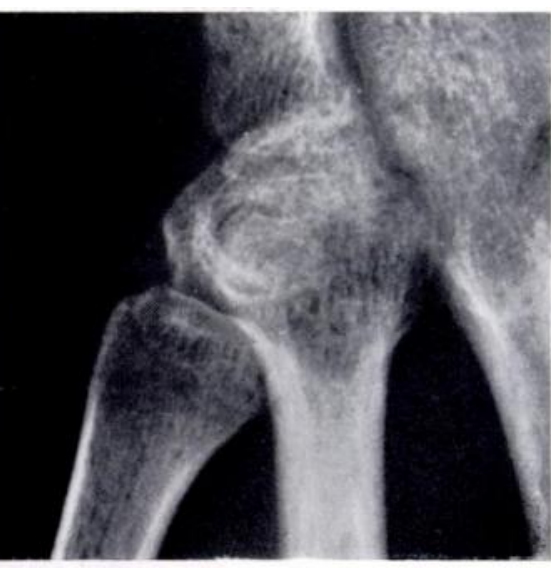

FIG. 10

Case 3. Figure 9-The radiograph shows a Group 2 fracture, but this was three weeks after injury, but before manipulation. Figure 10-A radiograph four weeks later shows a good position. 
Clinical results-Of the twenty-nine patients successfully treated by manipulation twenty-seven returned for a follow-up examination four weeks after removal of the plaster. Twenty-five patients had achieved a full range of thumb movements by this time. The two exceptions were reviewed again in a further month, by which time they had regained full movements.

Two patients failed to return for review after their plasters had been removed and could not ke traced when asked to attend for review. Both were labourers living in temporary lodgings. All the patients reviewed had returned to work within four weeks of having the plaster removed, but some were able to return before that time, and several were able to work while in plaster.

\section{ILLUSTRATIVE CASES}

Case 1-Figure 4 is a radiograph of a typical fracture in a thirty-three-year-old labourer with the volar fragment considerably rotated. Figure 5 shows the fracture after reduction and Figure 6 shows the result after removal of the plaster.

Case 2-Figures 7 and 8 show another patient with a considerable gap between the articular surfaces of the two fragments which was successfully reduced without anaesthetic.

Case 3-Figures 9 and 10 illustrate a Group 2 type of fracture occurring in a boy of sixteen years, who reported three weeks after he had injured his thumb by falling on it. It could be reduced readily without anaesthetic. Figure 10 shows the position four weeks later after removing the plaster. The subluxation was fully corrected and the fracture was united.

Case 4-A twenty-one-year-old clerk serving with the Women's Royal Army Corps was the only woman in the series. She injured her right thumb while playing hockey and reported the same day. Figure 11 shows the radiograph, and, though the displacement appears slight, clinically the metacarpal was very unstable and slipped very readily. No anaesthetic was required for reduction. Figure 12 shows the radiographs immediately after removal of the plaster. She also had osteopoikilosis.

\section{Analysis of two failures}

Case 5-A man aged twenty-four injured his right thumb during a fight (Fig. 13). Manipulation was performed without an anaesthetic the following day but was unsuccessful, and a further manipulation under brachial plexus block the next day was still unsuccessful.

Open operation was performed the following week using Ellis's method and a satisfactory reduction was obtained. No cause for the failure to reduce this fracture could be found.

Case 6-A thirty-six-year-old labourer reported three days after injuring his left thumb in a game of hurling. Figure 14 shows his original radiograph. A manipulation without anaesthetic was unsuccessful, but a second attempt using brachial plexus block anaesthesia was successful. However, two weeks later a check radiograph showed that the position had relapsed (Fig. 15). It can be seen from the radiograph that the site of the pressure was a little too proximal, overlying the anatomical snuff box, and this might explain the failure to maintain the reduction. Subsequently an operation was performed using Ellis's technique and a good position was obtained.

In both these patients the pins were removed six weeks after operation and good function was restored.

\section{ANAESTHESIA}

It proved possible to manipulate more than half the total number of fractures without any form of anaesthesia, and seventeen patients were treated in this way. The remainder were given some form of anaesthetic but they were mainly the earlier cases in the series when anaesthesia was assumed to be necessary (Table III).

VOl. $50 \mathrm{~B}$, NO. 1, FEBRUARY 1968 


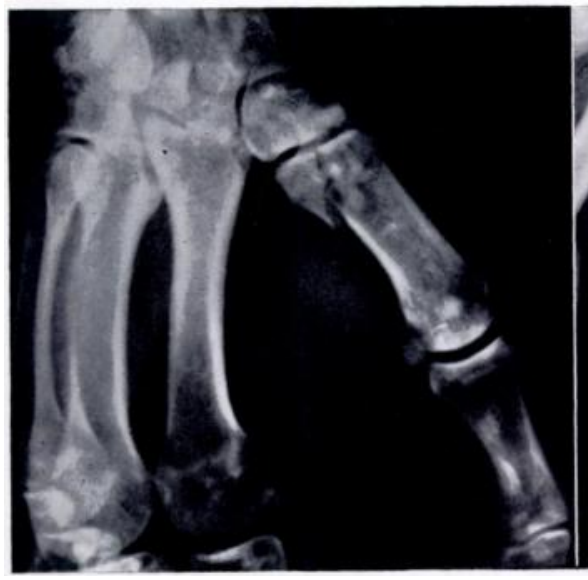

FIG. 11

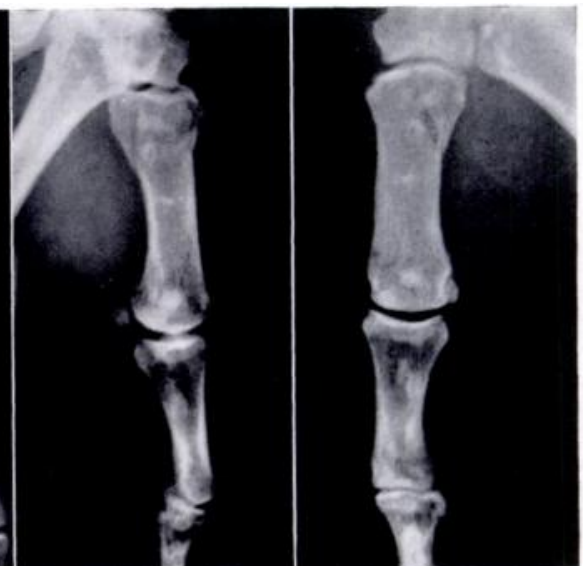

FIG. 12

Case 4. Figure 11-The radiograph shows a Group 2 fracture in a patient who also has osteopoikilosis. Figure 12-Two views of the fracture after reduction.

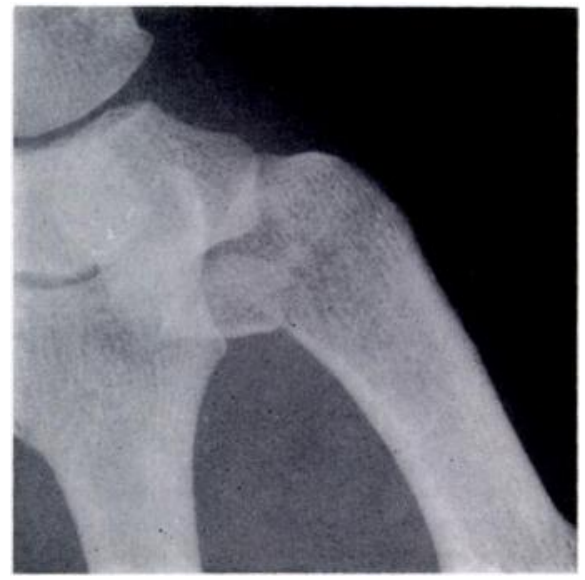

Fig. 13

Case 5-Radiograph before manipulation which failed to secure reduction. This was later achieved at open operation.

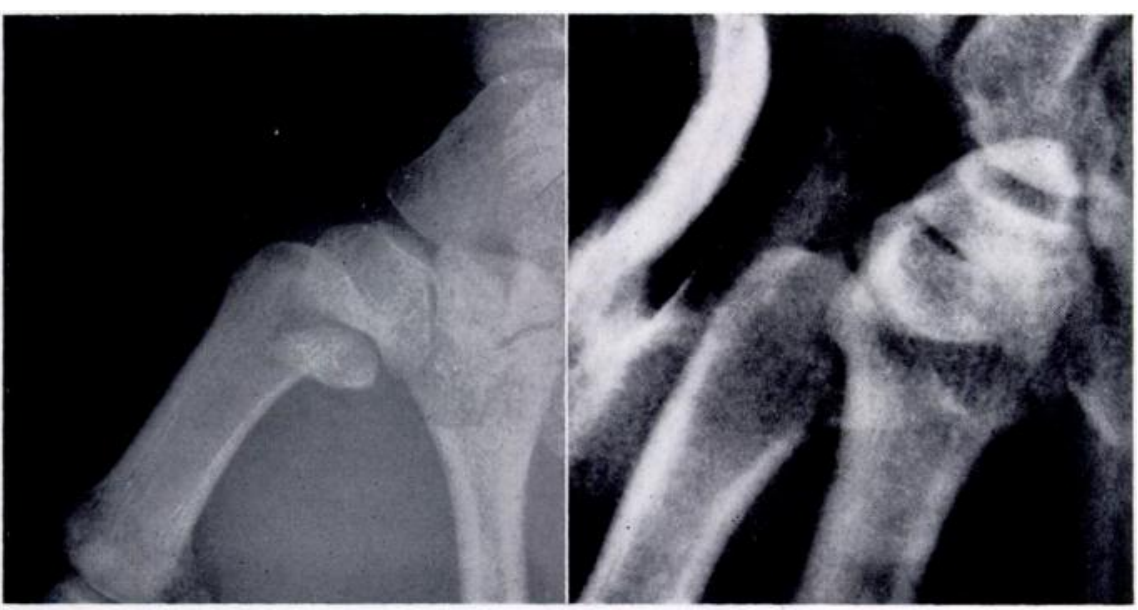

FIG. 14

Fig. 15

Case 6. Figure 14-The radiograph before manipulation. Figure 15-Two weeks later displacement has occurred. Open operation was necessary. 
Interval between injury and treatment-Charnley (1957) stated " A delay of four or five days seriously prejudices the ability to hold the reduction and late slipping is likely, and this is particularly the case if others have failed in previous attempts to reduce it." Griffiths (1964) also suggested that after a delay of four days or more there is no point in attempting reduction, as manipulation is likely to be unsuccessful.

TABLE III

Detalls of Anaesthesia Used

\begin{tabular}{|l|r|}
\hline No anaesthesia & 17 \\
\hline General anaesthesia . & 12 \\
\hline Brachial plexus block & 2 \\
\hline Total . & 31 \\
\hline
\end{tabular}

Seven fractures in this series were manipulated four or more days after the injury, and in all the procedure was successful. One patient was treated two weeks after injury, and two fractures were successfully reduced three weeks after injury, though it is noteworthy that these three fractures were all in Group 2.

The two failures were treated one and three days after injury respectively (Fig. 16). Obviously there must be a time limit after which manipulation will fail, though in Group 2 cases manipulation may be successful even after an interval of several weeks.

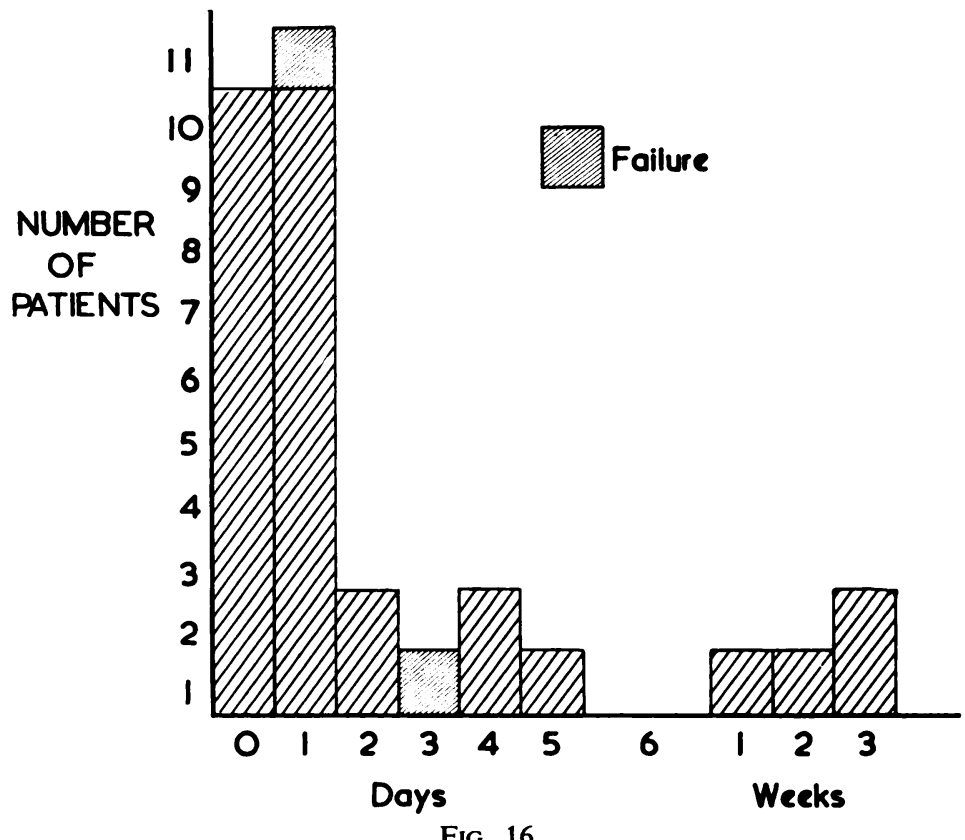

The time interval between injury and manipulation.

\section{COMPLICATIONS}

From the published accounts it seems that complications following open operation are rare. Iselin et al. (1956) noted one case of infection but other writers did not discuss complications.

The complications of the method of treatment described here are few and are of slight importance: Superficial skin ulceration occurred in three patients at the base of the metacarpal 
bone of the thumb. The ulcers had completely healed within two weeks of the removal of the plaster. Slight hypoaesthesia of the dorsum of the thumb occurred in three patients, but disappeared completely within a few days of the removal of the plaster. Presumably it was caused by compression of the cutaneous branches of the radial nerve; it was not found in the three cases where pressure ulceration of the skin occurred. Sensitivity to adhesive on the orthopaedic felt occurred once; the patient developed an eczematous rash of his hand and wrist which healed rapidly once the plaster was removed.

\section{DISCUSSION}

Opinions vary on the necessity for obtaining an accurate reduction of a Bennett's fracture. At one extreme Gedda (1954) maintained that anatomical reduction of the displacement is essential if a good result is to be obtained. Blum (1941) took an opposite view and stated that the essential feature for a good result was the development of a ball and socket joint, with the broadened metacarpal articular surface forming the socket. The quickest way to achieve this was not to attempt to reduce the fracture, but to encourage active movements and use of the thumb without immobilisation. Perkins (1958) supported this view, but stressed the importance of physiotherapy.

Griffiths' review (1964) of patients indicated that malunion is compatible with little or no symptoms, though some loss of movement is usual. This happy end is not invariably the case as a recent example illustrates. A twenty-year-old girl student injured her right thumb during a hockey match and sustained a Bennett's fracture. This was incompletely reduced at another hospital and some eight months later she was so severely disabled by pain that she could neither hold a pen to write nor grip a knife to cut her food. This injury eventually required an arthrodesis of the joint which resulted in a strong painless thumb though at the sacrifice of some movement.

The guiding principle in the treatment of this injury is accurate reduction of the displacement and the restoration of the articular surface of the metacarpal bone. This can be achieved in most cases by the manipulative technique described in this paper. Operative methods offer no advantages, because, with the exception of open reduction and screw fixation of the fragments, all other methods require plaster splintage for periods of four to eight weeks. It should be observed too that screw fixation is only suitable where there is a sufficiently large volar fragment to accept a screw. In general, operative methods should be reserved for the occasional case where conservative measures have failed.

There are a number of reasons for the poor results of closed treatment in the past. Firstly, the use of a faulty technique. There is no doubt that many fractures have been treated primarily by junior staff in casualty departments who may never have seen this injury before and have received no training in its correct management. It is a relatively uncommon injury and a doctor may not see a single case during a six-month tenure of a casualty officer's post. Secondly, the failure to manipulate and hold the reduction while the plaster is soft, and to maintain the pressure until the plaster has set. Finally, the over-emphasis on the importance of continuous traction upon the thumb.

\section{SUMMARY}

1. The treatment of Bennett's fracture is reviewed and the relative merits of conservative and operative treatment is considered.

2. A closed method of treatment is described and a series of thirty-one patients so treated is analysed. There were twenty-nine successful results.

3. It is urged that conservative treatment is the method of choice, and that operative measures should be reserved for the occasion when closed methods have failed.

Since this paper was submitted for publication, four more patients have been treated successfully by the method described, making a total of thirty-five patients. There has been no failure in the past six years. 
I am very grateful to Mr J. Crawford Adams, Mr G. L. Bonney, Mr B. Cashman and Mr A. J. Harrold for giving me the opportunity to treat patients under their care. I am particularly grateful to $\mathrm{Mr}$ Adams for many helpful suggestions embodied in this paper. I wish to thank Dr P. N. Cardew and the Department of Medical Photography of St Mary's Hospital for several of the photographs reproduced here.

\section{REFERENCES}

BADger, F. C. (1956): Internal Fixation in the Treatment of Bennett's Fractures. Journal of Bone and Joint Surgery, 38-B, 771.

Bennett, E. H. (1882): Fractures of the Metacarpal Bones. Dublin Journal of Medical Science, 73, 72.

Blum, L. (1941): The Treatment of Bennett's Fracture-Dislocation of the First Metacarpal Bone. Journal of Bone and Joint Surgery, 23, 578.

BöHLER, L. (1956): The Treatment of Fractures. Vol. 1. Fifth English edition. New York: Grune \& Stratton. Bunnell, S. (1956): Surgery of the Hand. Third edition. London: Pitman Medical Publishing Co. Ltd.

Charnley, J. (1957): The Closed Treatment of Common Fractures. Second edition. Edinburgh and London: E. \& S. Livingstone Ltd.

Clarkson, P., and Pelly, A. (1962): The General and Plastic Surgery of the Hand. Oxford: Blackwell Scientific Publications.

Creyssel, J., Mourgues, G. De, and Schnepp, J. (1959): Traitement des fractures articulaires de la base du premier métacarpien. Lyon Chirurgical, 55, 312.

Ehalt, W. (1929): Über Brüche des 1. Mittelhandknochens und ihre Behandlung. Archiv für orthopädische und Unfall-Chirurgie, 27, 515.

Ellis, V. H. (1946): A Method of Treating Bennett's Fracture. Proceedings of the Royal Society of Medicine, 39, 711.

FuRlong, R. (1957): Injuries of the Hand. London: J. \& A. Churchill Ltd.

Gedda, K.-O. (1954): Studies on Bennett's Fracture. Acta Chirurgica Scandinavica, Supplementum 193.

Gedda, K.-O., and Moberg, E. (1953): Open Reduction and Osteosynthesis of the So-Called Bennett's Fracture in the Carpo-metacarpal Joint of the Thumb. Acta Orthopaedica Scandinavica, 22, 249.

Griffiths, J. C. (1964): Fractures at the Base of the First Metacarpal Bone. Journal of Bone and Joint Surgery, 46-B, 712.

Iselin, M., Blanquernon, S., and Benoist, D. (1956): Fractures de la base du ler métacarpien. Mémoires de l'Académie de Chirurgie, 82, 771.

Johnson, E. C. (1944): Fracture of the Base of the Thumb. A New Method of Fixation. Journal of the American Medical Association, 126, 27.

LAMBotte, A. (1913): Chirurgie opératoire des fractures. Paris: Masson et Cie.

Lataste, J., and Cédard, C. (1959): Les fractures de la base du ler métacarpien. La Presse Médicale, 67, 610.

Menegaux, G., and Detrie, Ph. (1953): Le Traitement des fractures de la base du premier métacarpien. La Presse Médicale, 61, 257.

Miles, A., and Struthers, J. W. (1904): Bennett's Fracture of the Base of the Metacarpal Bone of the Thumb. Edinburgh Medical Journal, N.S. 15, 297.

Perkins, G. (1958): Fractures and Dislocations. London. University of London, The Athlone Press.

RAzemon, J.-P., and Lemerle, P. (1959): Les fractures de la base du premier métacarpien. Journal de Chirurgie, 78, 427.

Roberts, N. (1938): Fractures of the Phalanges of the Hand and Metacarpals. Proceedings of the Royal Society of Medicine, 31, 793.

Robins, R. H. C. (1961): Injuries and Infections of the Hand. London: Edward Arnold (Publishers) Ltd.

Robinson, S. (1908): The Bennett Fracture of the First Metacarpal Bone. Diagnosis and Treatment. Boston Medical and Surgical Journal, 158, 275.

SPÅNGBeRG, O., and ThORÉN, L. (1963): Bennett's Fracture. Journal of Bone and Joint Surgery, 45-B, 732.

VAughan-JaCKSON, O. J. (1956): Internal Fixation in the Treatment of Bennett's Fractures. Journal of Bone and Joint Surgery, 38-B, 771.

WAGNER, C. J. (1950): Method of Treatment of Bennett's Fracture Dislocation. American Journal of Surgery, 80, 230.

WAGNer, C. J. (1951): Transarticular Fixation of Fracture-Dislocations of the First Metacarpal-carpal Joint. Western Journal of Surgery, Obstetrics and Gynecology, 59, 362.

WATSON-Jones, R. (1955): Fractures and Joint Injuries. Fourth edition, Volume 2. Edinburgh and London: E. \& S. Livingstone Ltd.

Wiggins, H. E., Bundens, W. D., Jun., and Park, B. J. (1954): A Method of Treatment of Fracture-dislocations of the First Metacarpal Bone. Journal of Bone and Joint Surgery, 36-A, 810.

VOL. 50 B, NO. 1, FEBRUARY 1968 